Marquette University

e-Publications@Marquette

Biomedical Engineering Faculty Research and

Publications

Biomedical Engineering, Department of

$11-15-2007$

\title{
Mechanical Behavior and Failure Analysis of Prosthetic Retaining \\ Screws after Long-Term Use In Vivo. Part 2: Metallurgical and \\ Microhardness Analysis
}

\author{
Youssef S. Al Jabbari \\ King Saud University \\ Raymond Fournelle \\ Marquette University, raymond.fournelle@marquette.edu \\ Gerald J. Ziebert \\ Marquette University \\ Jeffrey M. Toth \\ Marquette University, jeffrey.toth@marquette.edu \\ Anthony lacopino \\ University of Manitoba
}

Follow this and additional works at: https://epublications.marquette.edu/bioengin_fac

Part of the Biomedical Engineering and Bioengineering Commons

\section{Recommended Citation}

Al Jabbari, Youssef S.; Fournelle, Raymond; Ziebert, Gerald J.; Toth, Jeffrey M.; and lacopino, Anthony, "Mechanical Behavior and Failure Analysis of Prosthetic Retaining Screws after Long-Term Use In Vivo. Part 2: Metallurgical and Microhardness Analysis" (2007). Biomedical Engineering Faculty Research and Publications. 551.

https://epublications.marquette.edu/bioengin_fac/551 


\section{Marquette University}

\section{e-Publications@Marquette}

\section{Biomedical Engineering Faculty Research and Publications/College of Engineering}

This paper is NOT THE PUBLISHED VERSION; but the author's final, peer-reviewed manuscript. The published version may be accessed by following the link in the citation below.

Journal of Prosthodontics, Vol. 17, No. 3 (April 2008): 181-191. DOI. This article is (C) Wiley and permission has been granted for this version to appear in e-Publications@Marquette. Wiley does not grant permission for this article to be further copied/distributed or hosted elsewhere without the express permission from Wiley.

\section{Contents}

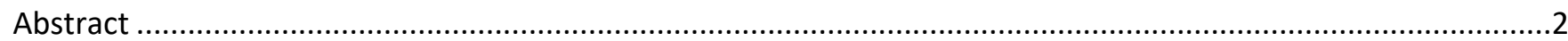

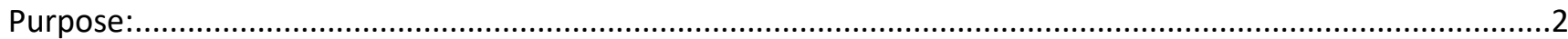

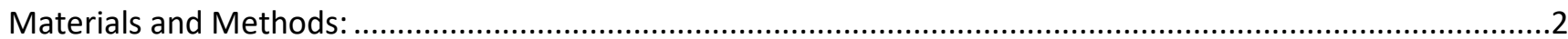

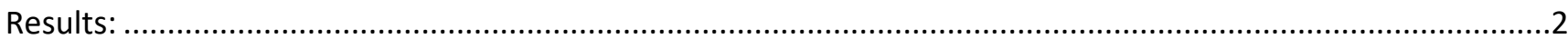

Conclusions:

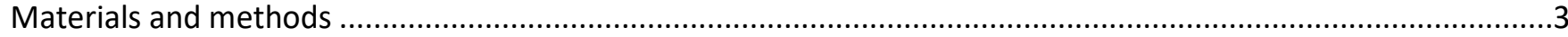

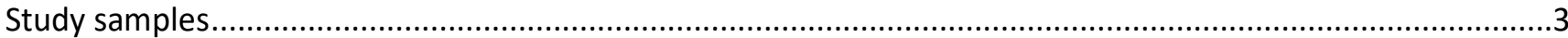

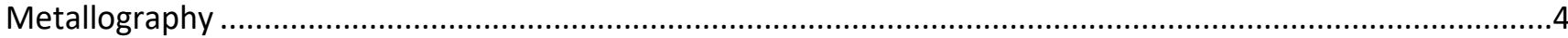

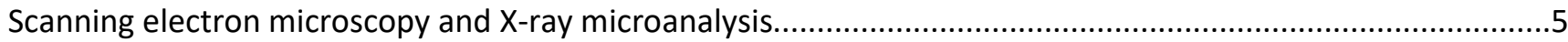

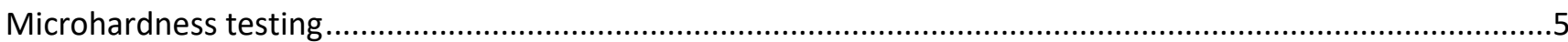

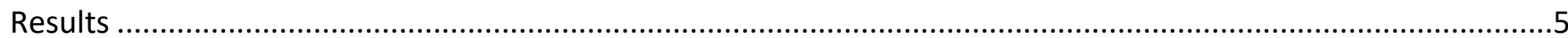

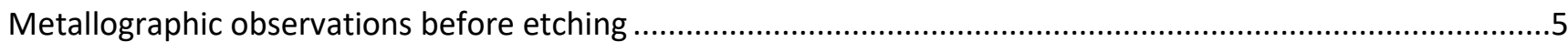

Microstructural observations after etching and X-ray microanalysis of screws/screw constituents ..................8

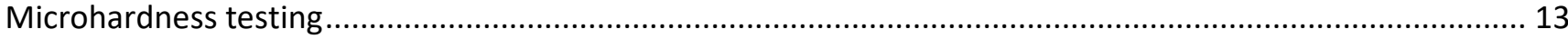

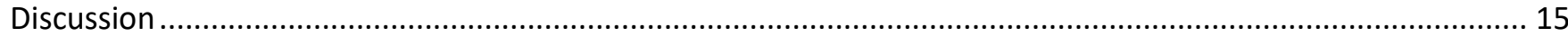

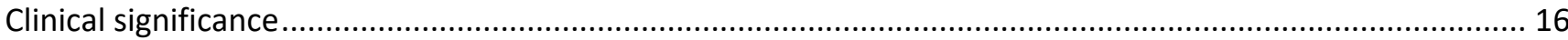

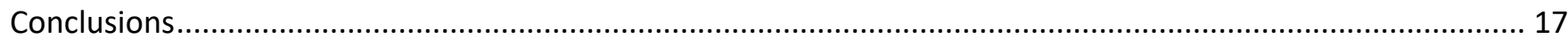

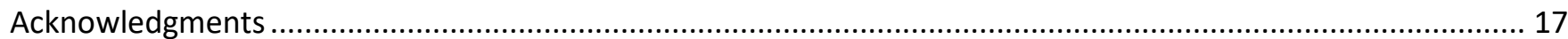




\section{Mechanical Behavior and Failure Analysis of Prosthetic Retaining Screws after Long-Term Use In Vivo. Part 2: Metallurgical and Microhardness Analysis}

Youssef Al Jabbari

School of Dentistry, Marquette University, Milwaukee, WI

Raymond Fournelle

Mechanical and Industrial Engineering, Marquette University, Milwaukee, WI

Gerald Ziebert

School of Dentistry, Marquette University, Milwaukee, WI

Jeffrey Toth

School of Dentistry, Marquette University, Milwaukee, WI

Anthony lacopino

University of Manitoba of Faculty Dentistry, Winnipeg, Manitoba, Canada

\section{Abstract}

Purpose: This study involved testing and analyzing multiple retrieved prosthetic retaining screws after longterm use in vivo to: (1) detect manufacturing defects that could affect in-service behavior; (2) characterize the microstructure and alloy composition; and (3) further characterize the wear mechanism of the screw threads.

Materials and Methods: Two new (control) screws from Nobel Biocare (NB) and 18 used (in service 18120 months) retaining screws [12 from NB and 6 from Sterngold (SG)] were: (1) metallographically examined by light microscopy and scanning electron microscopy (SEM) to determine the microstructure; (2) analyzed by energy dispersive X-ray (EDX) microanalysis to determine the qualitative and semiquantitative average alloy and individual phase compositions; and (3) tested for Vickers microhardness.

Results: Examination of polished longitudinal sections of the screws using light microscopy revealed a significant defect in only one Group 4 screw. No significant defects in any other screws were observed. The defect was considered a "seam" originating as a "hot tear" during original casting solidification of the alloy. Additionally, the examination of longitudinal sections of the screws revealed a uniform homogeneous microstructure in some groups, while in other groups the sections exhibited rows of second phase particles. The screws for some groups demonstrated severe deformation of the lower threads and the bottom part of the screw leading to the formation of crevices and grooves. Some NB screws were comprised of Au-based alloy with 
$\mathrm{Pt}, \mathrm{Cu}$, and $\mathrm{Ag}$ as alloy elements, while others (Groups 4 and 19) were Pd-based with $\mathrm{Ga}, \mathrm{Cu}$, and Au alloy elements. The microstructure was homogeneous with fine or equiaxed grains for all groups except Group 4, which appeared inhomogeneous with anomalous grains. SG screws demonstrated a typical dendritic structure and were Au-based alloy with $\mathrm{Cu}$ and $\mathrm{Ag}$ alloy elements. There were differences in the microhardness of gold alloy screws from NB and SG as well as palladium alloy screws from NB.

Conclusions: Significant differences within NB retaining screws and between NB and SG screws were found for microstructure, major alloy constituents, and microhardness.

Despite the high success and predictability of rehabilitating patients with osseointegrated implants, the problem of retaining screw loosening and/or fracture has resulted in many efforts by clinicians and/or manufacturers to decrease the occurrence of these problems. ${ }^{1,2}$ To avoid screw loosening, many manufacturers refined the design of the various implant component interfaces to achieve a better and more predictable tightening method. ${ }^{1}$ Gold alloy screws became preferable to titanium alloy screws primarily because of the larger frictional resistance between mating male and female threads of titanium alloy screws. ${ }^{1}$ The lower coefficient of friction of gold alloy screws allows higher preload values. ${ }^{2}$ Both $3 \mathrm{i}$ (3i Implant Innovation, Inc., West Palm Beach, FL) and Ster-Oss (Nobel Biocare USA, Yorba Linda, CA) implant systems modified the surfaces of the screws to reduce the coefficient of friction between mating threads, increasing preload values. ${ }^{1} \mathrm{3i}$ added dry lubricant coatings, whereas Ster-Oss used a treatment process that also increases fatigue strength. ${ }^{1}$ It has been demonstrated that when a $0.8-\mu \mathrm{m}$ pure gold coating (dry lubricant coating) is applied to the screw and screw threads, preload values are increased by $24 \%{ }^{3}$ Currently, the gold content of gold alloy screws ranges from 2 to $64 \%$ depending on the manufacturer. ${ }^{2}$ Until recently, there was only one published report regarding microstructure and major alloy composition of retaining and/or abutment screws. ${ }^{4}$ All other available data are primarily manufacturerbased.

The first metallographic analysis examining screw microstructure determined the major constituents of four retaining screws from two manufacturers. ${ }^{4}$ Qualitative elemental analysis of these new screws revealed that the alloy of Nobel Biocare (NB) screws was mainly gold-based, whereas the alloy of $3 \mathrm{i}$ screws was mainly palladiumbased. Before etching, rows of particles on the longitudinal sections of the screws were observed. These were identified as "stringers," which may represent a second phase in the alloy; however, the study did not determine the alloy elements in the stringers. No significant manufacturing defects were found in the screws examined. Surface or subsurface defects (such as volumetric porosity, inclusions, and/or cracks) can act as stress raisers, reducing screw fatigue life under repeated functional bite forces. ${ }^{5}$ To date, there is no published data indicating the occurrence of manufacturing defects in retaining and/or abutment screws after use in vivo. This study analyzed and tested multiple retrieved prosthetic retaining screws after long-term use in vivo aiming to: (1) detect manufacturing defects affecting in-service behavior; (2) determine the microstructure and alloy composition; and (3) further characterize the wear mechanism of the screw threads.

\section{Materials and methods}

\section{Study samples}

Two new (control) and 18 used retaining screws (a total of 20 screws; one representative screw from each test group in Table 1 of Part 1 of this series) were subjected to three types of examination and testing: (1) light microscopy; (2) scanning electron microscopy (SEM) and energy dispersive X-ray (EDX) microanalysis; and (3) microhardness measurements. The selected representative screw from each group was one of the most anterior three of the retaining screws. For further details regarding screw group classification used in this study, screw inservice history, and type and manufacturer of control and retrieved screws, refer to Table 1 in Part 1 of this series. 
Table 1. Average overall composition of metal alloys for all tested prosthetic retaining screw groups as determined by EDX

\begin{tabular}{|c|c|c|c|c|c|c|c|}
\hline \multirow[t]{2}{*}{ Group number } & \multicolumn{7}{|c|}{ Wt\% of detected elements } \\
\hline & $\mathrm{Au}$ & Pd & Pt & Ga & $\mathrm{Cu}$ & $\mathrm{Ag}$ & $\mathrm{Fe}$ \\
\hline 1 & 68 & & 14 & & 9 & 9 & $<1 \%$ \\
\hline 2 & 66 & & 16 & & 9 & 8 & $<1 \%$ \\
\hline 3 & 64 & & 16 & & 9 & 11 & $<1 \%$ \\
\hline 4 (Light area) & 2 & 71 & & 15 & 11 & & $<1 \%$ \\
\hline 4 (Dark area) & 2 & 71 & & 15 & 10 & & $<1 \%$ \\
\hline 5 & 62 & & 17 & & 9 & 12 & $<1 \%$ \\
\hline 6 & 66 & & 16 & & 9 & 9 & $<1 \%$ \\
\hline 7 & 68 & & 14 & & 9 & 9 & $<1 \%$ \\
\hline 8 & 64 & & 15 & & 9 & 12 & $<1 \%$ \\
\hline 9 & 66 & & 16 & & 9 & 9 & $<1 \%$ \\
\hline 10 & 63 & & 16 & & 9 & 11 & $<1 \%$ \\
\hline 11 & 65 & & 15 & & 9 & 10 & $<1 \%$ \\
\hline 12 & 76 & & & & 15 & 9 & $<1 \%$ \\
\hline 13 & 78 & & & & 13 & 8 & $<1 \%$ \\
\hline 14 & 76 & & & & 14 & 10 & $<1 \%$ \\
\hline 15 & 65 & & 15 & & 9 & 10 & $<1 \%$ \\
\hline 16 & 76 & & & & 14 & 9 & $<1 \%$ \\
\hline 17 & 76 & & & & 14 & 9 & $<1 \%$ \\
\hline 18 & 66 & & 15 & & 9 & 9 & $<1 \%$ \\
\hline 19 & 2 & 71 & & 16 & 11 & & $<1 \%$ \\
\hline 20 & 76 & & & & 14 & 9 & $<1 \%$ \\
\hline
\end{tabular}

\section{Metallography}

To microscopically examine the longitudinal section of a screw, the screw was positioned at the bottom of a cylindrical reusable plastic mold mounting cup (Buehler Sample-Kup, Buehler Ltd, Waukegan, IL) such that its 
long axis was parallel to the bottom of the mold, allowing resin material to flow around the threads of the screw. Epoxicure resin material was mixed with Epoxicure hardener (Buehler Ltd) according to manufacturer instructions (5/1) and poured into the mold under atmospheric pressure. The entire plastic mold was then placed in a dessicator and partially evacuated to remove all air bubbles from the epoxy, after which it was allowed to cure for 8 hours at room temperature.

The specimen section surface was initially ground with silicone carbide abrasive paper ( 80 and 120 grit) on a belt grinder (Leco Ltd, St Josephs, MI) until the longitudinal section was exposed. The section surface of the specimen was then hand-ground with 240,320, 400, and 600 grit abrasive silicon carbide papers (Handimet Grinder, Buehler Ltd) until the center of the specimen was reached. Polishing was accomplished with Metadi diamond polishing compounds (Buehler Ltd) with three different particle sizes ( $9 \mu \mathrm{m}, 1 \mu \mathrm{m}$, and $1 / 4 \mu \mathrm{m})$. The final polished metallographic specimen was chemically etched by immersion in a freshly prepared solution of $45 \%$ hydrochloric acid, $25 \%$ nitric acid, and 30\% tap water for 15 seconds. When the surface demonstrated a frosted appearance, it was considered fully etched. The etched surface was then examined at low $(\times 25, \times 100)$ and high $(\times 200, \times 500)$ magnifications using an Olympus Model MPE3 light microscope (Olympus Optical Co., Tokyo, Japan).

\section{Scanning electron microscopy and X-ray microanalysis}

SEM and EDX microanalysis were performed on the same specimens used for light microscopy to characterize their microstructural details and to establish their overall chemical and phase compositions. Semiquantitative analysis was performed using the SQ program Tracor Northern Series II X-ray analyzer (Tracor Northern, Inc., Middleton, WI). The SEM was operated at $25 \mathrm{Kev}$ using secondary electron imaging. Epoxy mounts were made conductive by coating them with carbon using a Denton Model DV-515 vacuum evaporator (Denton Vacuum, Inc., Cherry Hill, NJ).

\section{Microhardness testing}

Vickers microhardness testing was performed on the same specimens used for light microscopy to determine the overall average hardness of screw material as well as the microhardness of some microstructural constituents. The average screw hardness was determined by a Kentron microhardness tester (Torsion Balance Company, Clifton, NJ) with a Vickers diamond pyramid and a load of $600 \mathrm{gm}$. A 25-gm load was used for determining the hardness of the second phase particles. For all testing, a load application time of 15 seconds with a dwell time of 15 seconds was used. Five recordings were used to obtain the average hardness for each specimen.

\section{Results}

\section{Metallographic observations before etching}

Examination of polished longitudinal sections of the screws with the light microscope at low and high magnifications revealed a significant defect in only one Group 4 screw. No significant defects in any other screws were observed. The defect is very similar to the external crack observed under SEM examination of screw $4 \mathrm{~A}_{1}$ (Group 4) in Part 1 of this series. This was considered a "seam" in a drawn wire originating as a "hot tear" during original casting solidification of the alloy. At low magnification $(\times 25)$, the crack (elongated voids) was parallel to the long axis of the screw, and, as indicated by arrows in Figure $1 \mathrm{~A}$, it extends along the entire length of the screw. Under higher magnification $(\times 100)$, the crack extends almost the full length of the head-shank area and begins as a hairline crack before it reappears as a larger crack in the middle and bottom parts of the threaded areas (Figs 1B, C). 


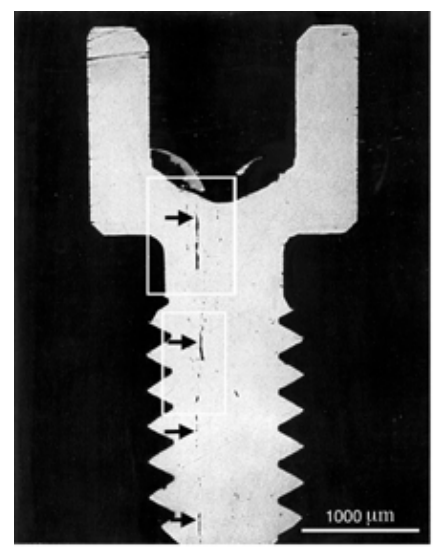

(A)

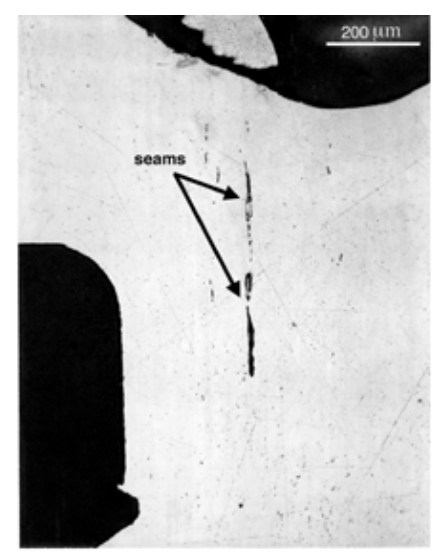

(B)

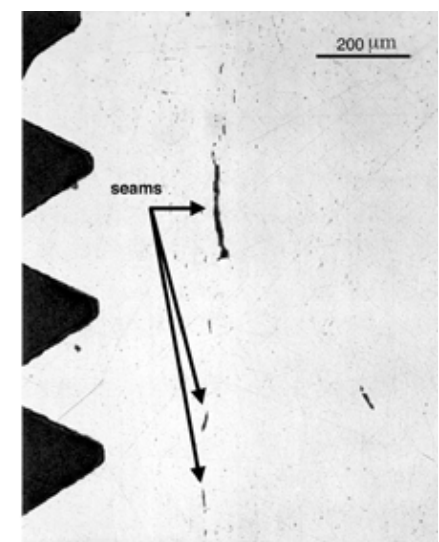

(C)

Figure 1. Light micrographs of a polished and unetched longitudinal section of the $4 \mathrm{~A}_{3}$ prosthetic screw. The specimen demonstrates an internal crack-like defect (seam) as indicated by arrows. Outlined two areas in (A) at $\times 25$ are shown in (B) and (C) at $\times 100$.

At low magnification ( $\times 25)$, the microstructure of screws in Groups $1,2,8,9,11,15$, and 18 appeared similar to what is shown in Figure 2. In Figure 2A, rows of second phase particles identified as "stringers" aligned along the long axis of the screw can be observed. Under higher magnification $(\times 500)$, the stringer appeared to be made up of elongated second phase particles parallel to the direction of cold working on the as-polished surface of the screw (Fig 2B). The microstructure of screws in Groups 3, 5-7, 10, 12-14, 16, 17, 19, and 20 appeared homogeneous with no major second phase particles. At low and high magnifications, the screws for Groups 3, 5, 6,8 , and 11 exhibited severe deformation of the lower threads and the bottom part of the screw, leading to the formation of crevices and grooves (Figs 3 and 4). A lack of uniformity of thread wear patterns was observed on each severely deformed screw. Figure 5 shows the development of thread wear and subsequent extrusion of surface material leading to surface roughness on thread crests, flanks, and roots. This extrusion of material is consistent with that shown by SEM in Part 1 of this series and further supports the proposed mechanism of adhesive wear.

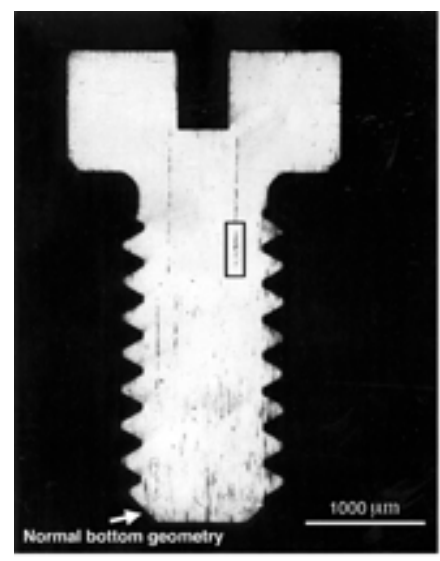

(A)

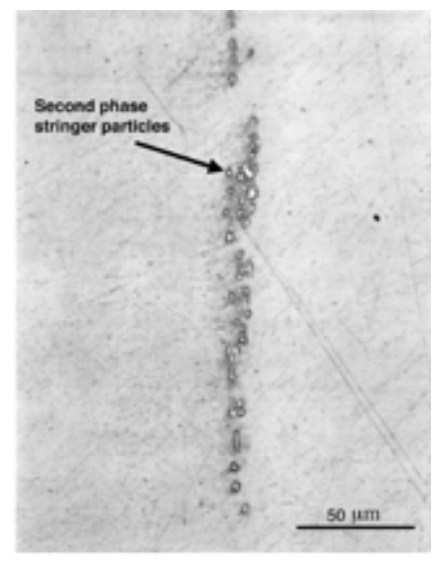

(B)

Figure 2. Light micrographs of a polished and unetched longitudinal section of the $1 \mathrm{~A}_{3}$ prosthetic screw (control). Outlined area in (A) at $\times 25$ is shown in (B) at $\times 500$ magnification. Note the normal geometrical appearance of the bottom of the screw and the second phase particles in stringers parallel to the longitudinal direction of the screw. 


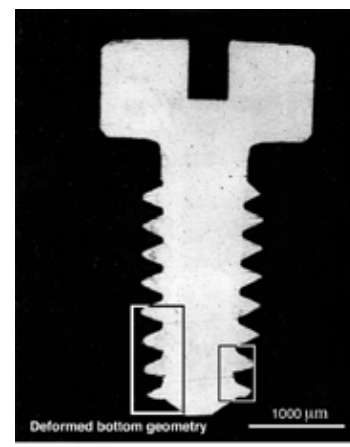

(A)

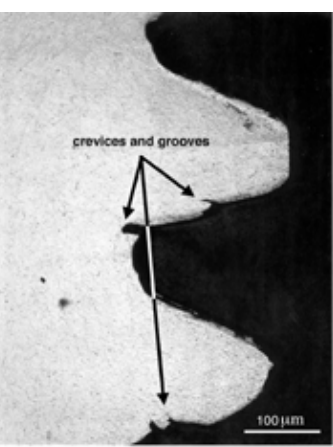

(B)

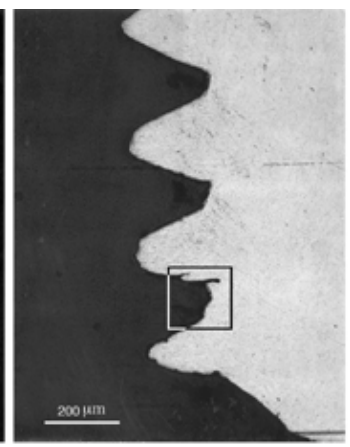

(C)

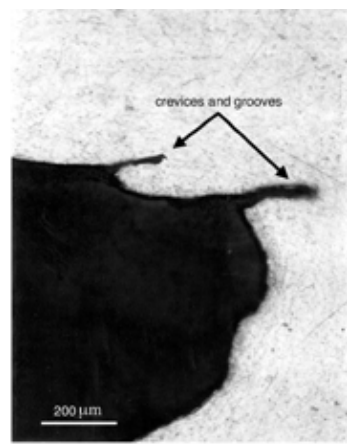

(D)

Figure 3. Light micrographs of a polished and unetched longitudinal section of the $3 A_{3}$ prosthetic screw. The outlined areas in (A) at $\times 25$ are shown in (B) at $\times 200$ and in (C) at $\times 100$ magnifications. The outlined area in (C) is shown in (D) at $\times 500$. Note the lack of uniformity of thread wear patterns as well as the crevices and grooves in the lower threads.

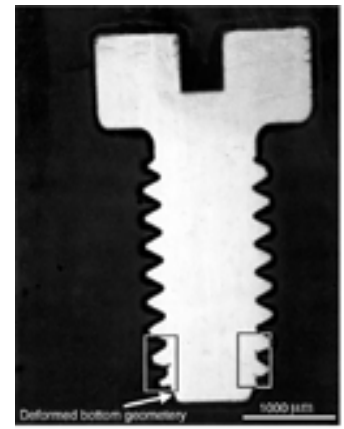

(A)

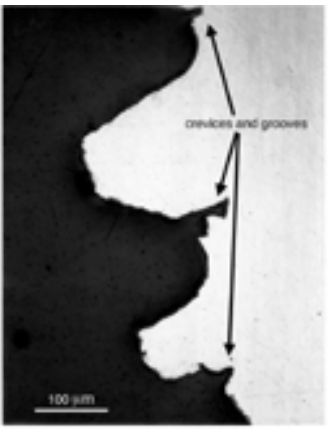

(B)

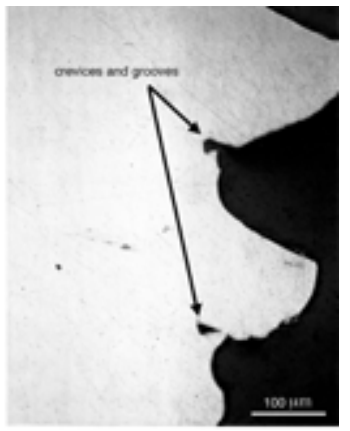

(C)

Figure 4. Light micrographs of a polished and unetched longitudinal section of the $5 \mathrm{~A}_{3}$ prosthetic screw. The outlined areas in (A) at $\times 25$ are shown in (B) and (C) at $\times 200$ magnification. Note the lack of uniformity of the thread wear pattern.

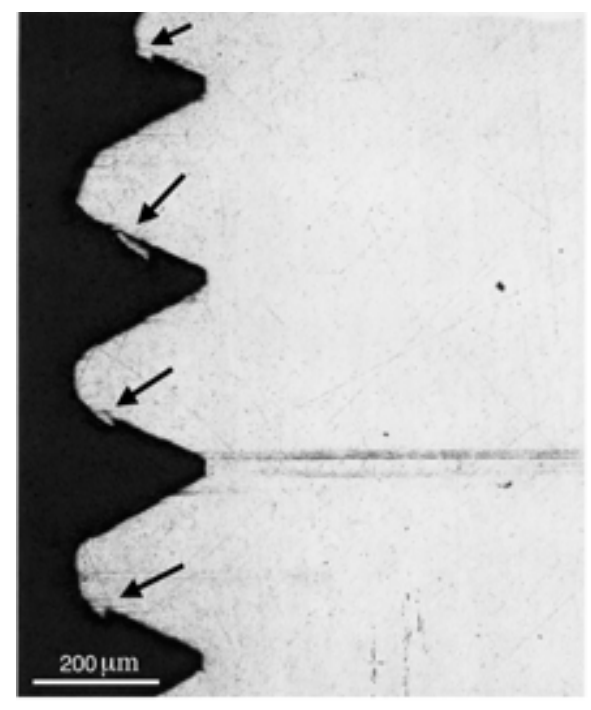

(A)

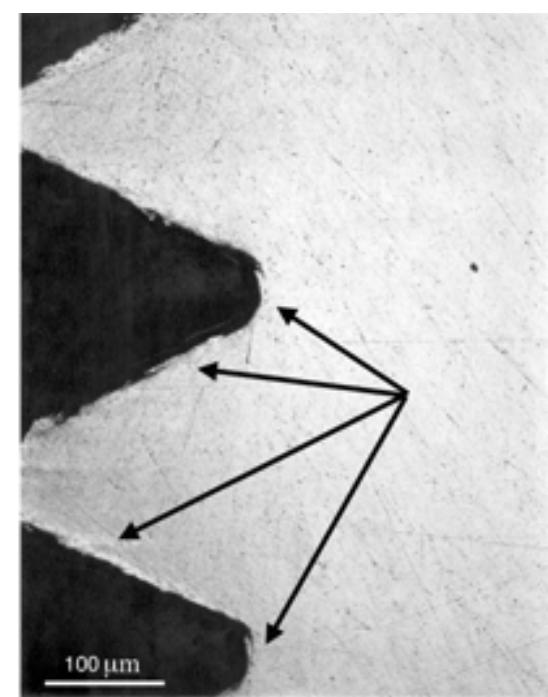

(B) 
Figure 5.Light micrographs of polished and unetched longitudinal sections of the $6 A_{3}$ and $8 A_{3}$ prosthetic screws. The $6 A_{3}$ prosthetic screw $(A)$ at $\times 100$ and the $8 A_{3}$ prosthetic screw $(B)$ at $\times 200$ magnification showing surface material extrusion as a result of adhesive wear involving thread crests, flanks, and roots (arrows).

\section{Microstructural observations after etching and X-ray microanalysis of screws/screw constituents}

Figures 6-14 illustrate the microstructure of screws along with EDX plots of relative X-ray intensity versus X-ray photon energy (Kev) for each tested group. The weight percentages for the elements determined from the spectra are shown in Table 1. The microstructure of a Group 1 screw (control) is shown in Figure 6. The second phase stringers are elongated along the screw axis as a result of cold or hot working. Figure $6 \mathrm{~B}$ is a higher magnification $(\times 200)$ view of the thread area demonstrating that the flow lines of the extremely fine elongated grains in thread areas end at the thread flanks, indicating that the threads were formed by machining (cut threading). Under higher magnification $(\times 500)$, the elongated stringers appear to consist of small light etching second phase particles (Fig 6C). All etched surfaces of the screws for Groups 2, 7, 9, 11, 15, and 18 appeared similar to what is seen in Figure 6.

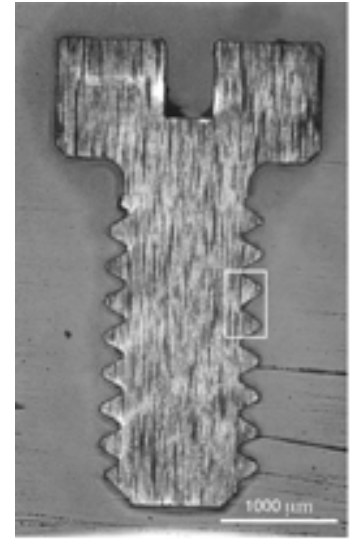

(A)

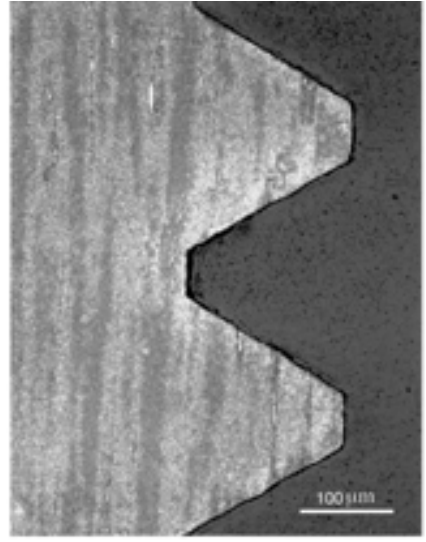

(B)

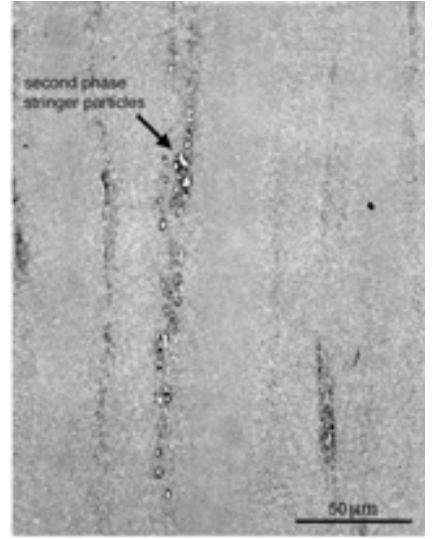

(C)

Figure 6. Light micrograph of the $1 A_{3}$ prosthetic screw (control) after etching. Note the elongated fine grains along the screw axis: (A) at $\times 25,(B)$ at $\times 200$ of outlined area in (A), and (C) at $\times 500$. Additionally note the nondeformed flow lines ending at the thread flank indicating "machine threading."

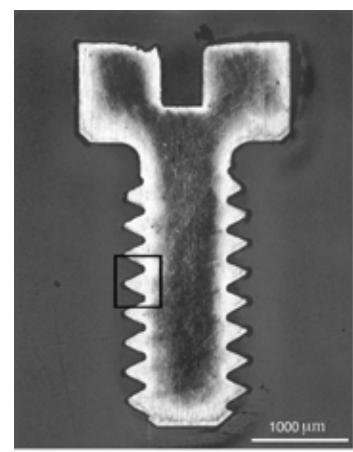

(A)

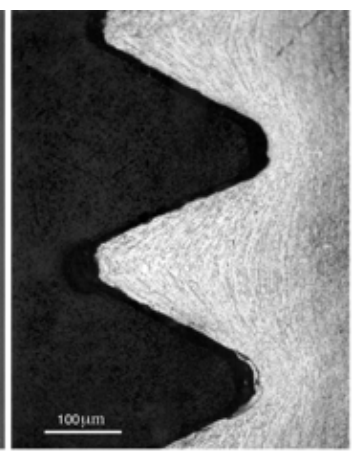

(B)

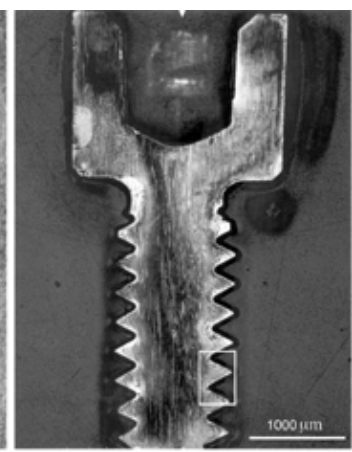

(C)

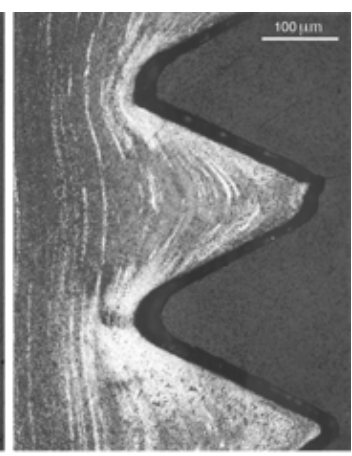

(D)

Figure 7. Light micrographs of prosthetic screws $5 A_{3}$ and $8 A_{3}$ after etching. Note that the screws $5 A_{3}(A \& B)$ and $8 A_{3}$ (C\&D) demonstrate elongated fine grains along screw axis: $(A)$ and $(C)$ are at $\times 25$, whereas $(B)$ and $(D)$ are at $\times 200$ enlargements of the outlined area in (A) and (C), respectively. Additionally, note that at high magnification, the deformation flow lines follow individual thread contour, indicating "roll threading." 


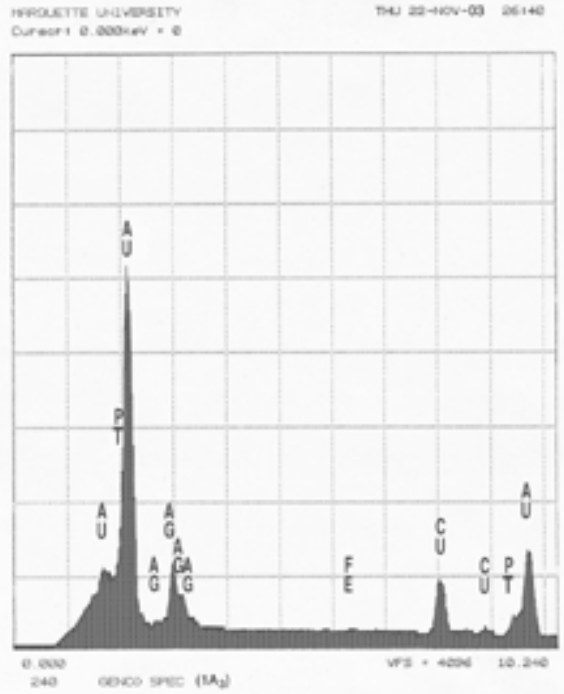

(A)

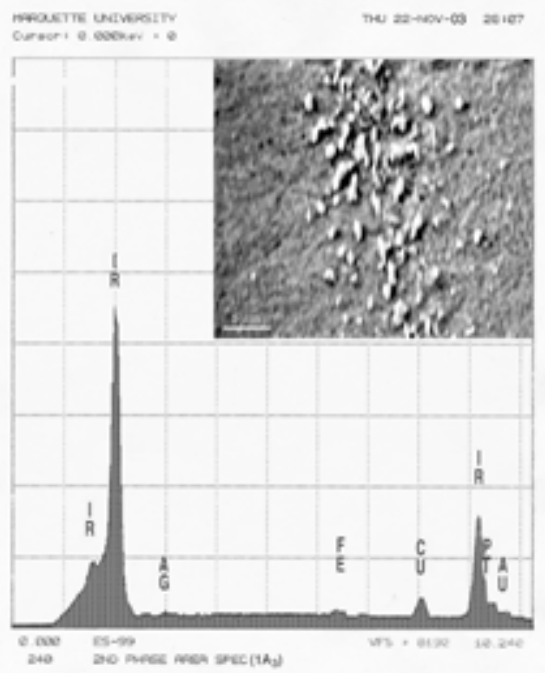

(B)

Figure 8. (A) EDS X-ray spectrum for the overall structure of $1 A_{3}$ screw shown in Figure 6. (B) EDS X-ray spectrum for second phase stringers of $1 A_{3}$ screw shown in Figure $6 C$. On the top right is the SEM micrograph of the analyzed region at $\times 3000$.

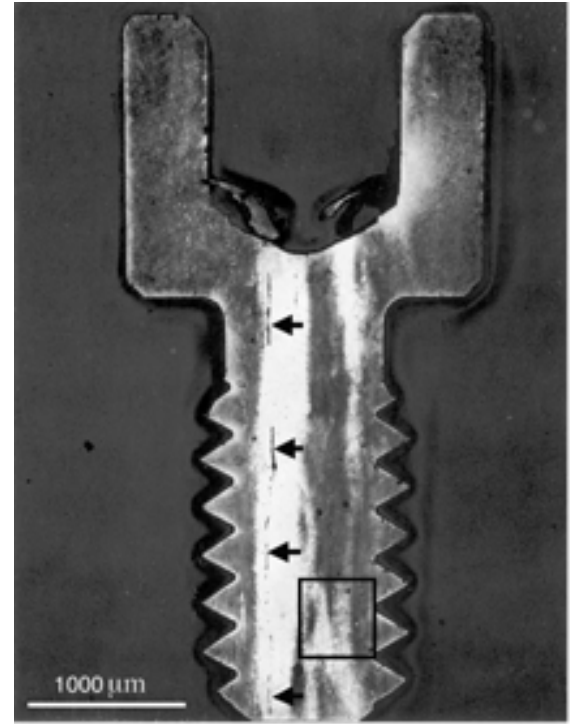

(A)

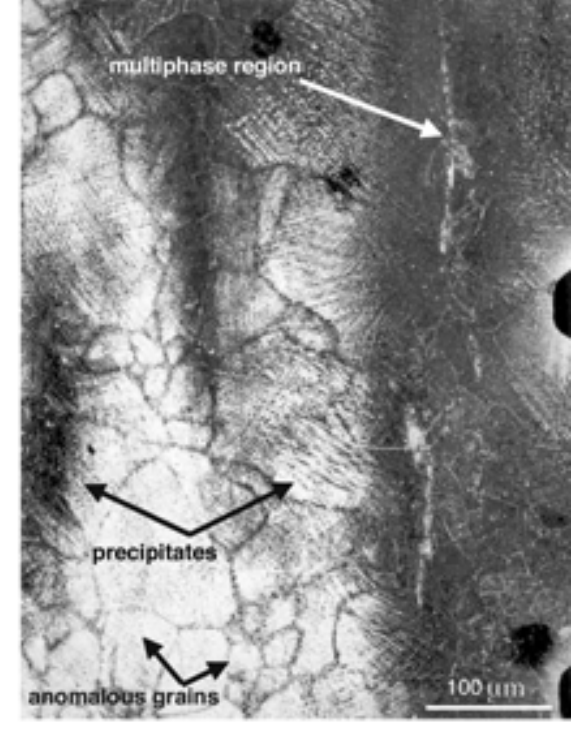

(B)

Figure 9. Light micrograph after etching of $4 A_{3}$ screw showing a very inhomogeneous microstructure: $(A)$ at $\times 25$, (B) at $\times 200$ of outlined area in (A). Note that the etching served to accentuate the crack-like defect (hot tears). 
Cursor: 0. 0eokel a

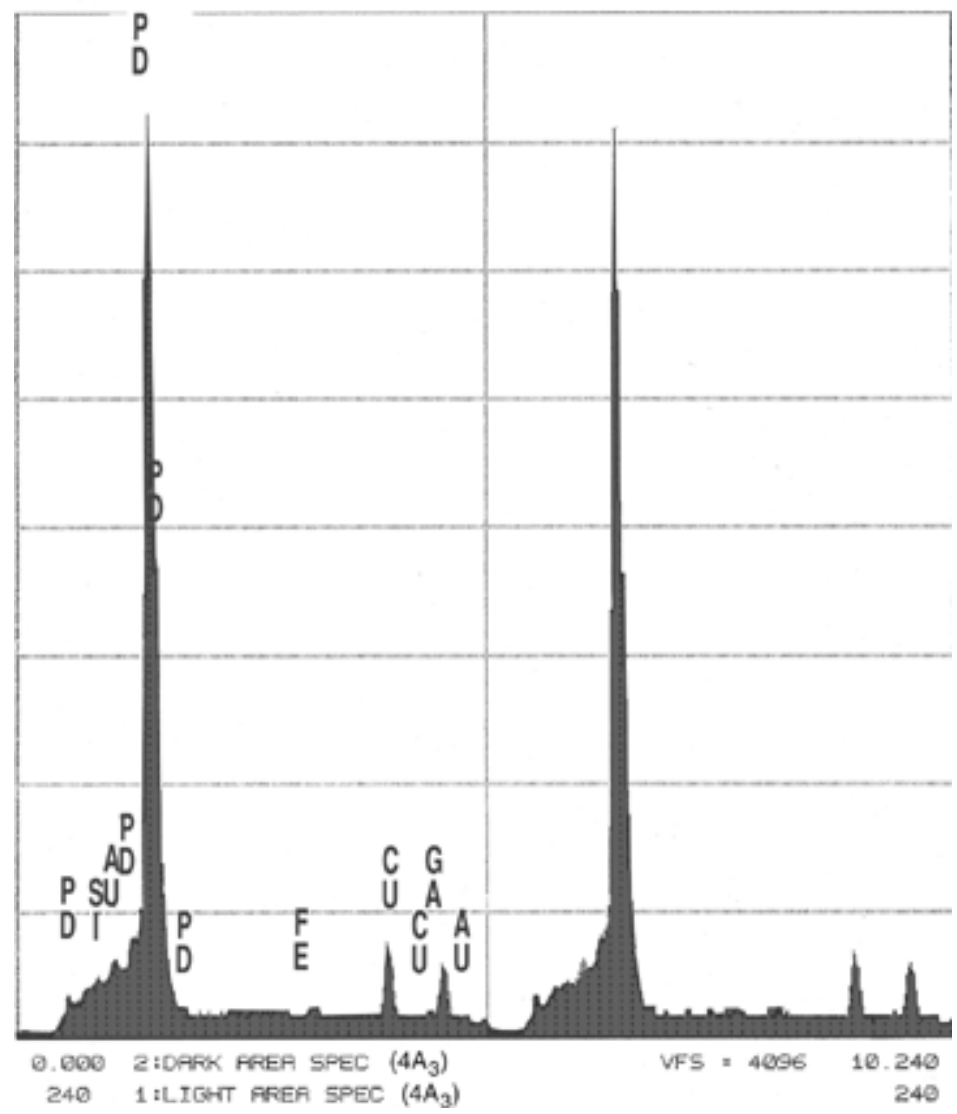

Figure 10. Comparing EDS X-ray spectrums of dark and light areas shows similar peaks with similar intensities of overall structure for $4 A_{3}$ screw shown in Figure 9.

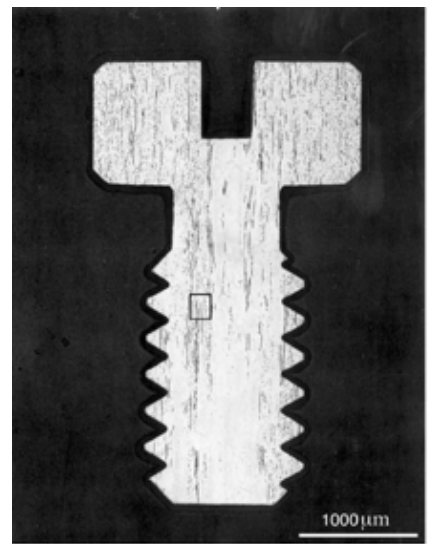

(A)

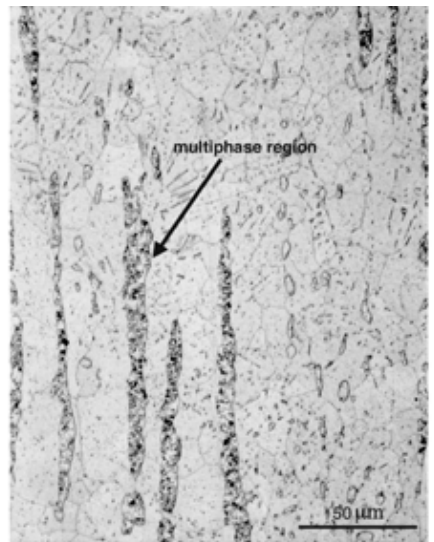

(B)

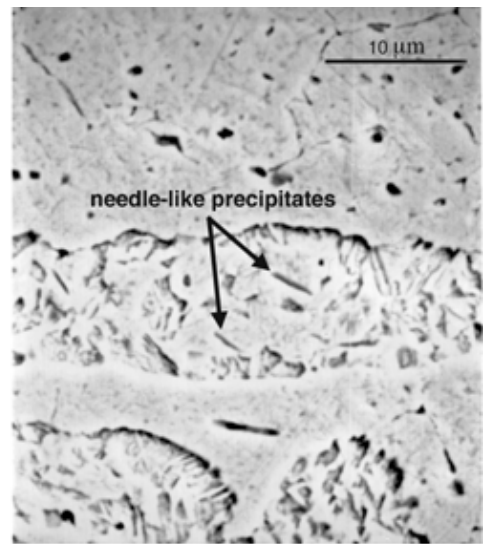

(C)

Figure 11. Light micrograph after etching of $19 A_{3}$ screw showing a homogeneous microstructure with elongated second phase particles: (A) at $\times 25,(B)$ at $\times 200$ of outlined area in (A). (C) SEM photomicrograph at $\times 2700$ showing multiphase particle. Note in (C) light periphery associated with multiphase particle and needle-like precipitates. 


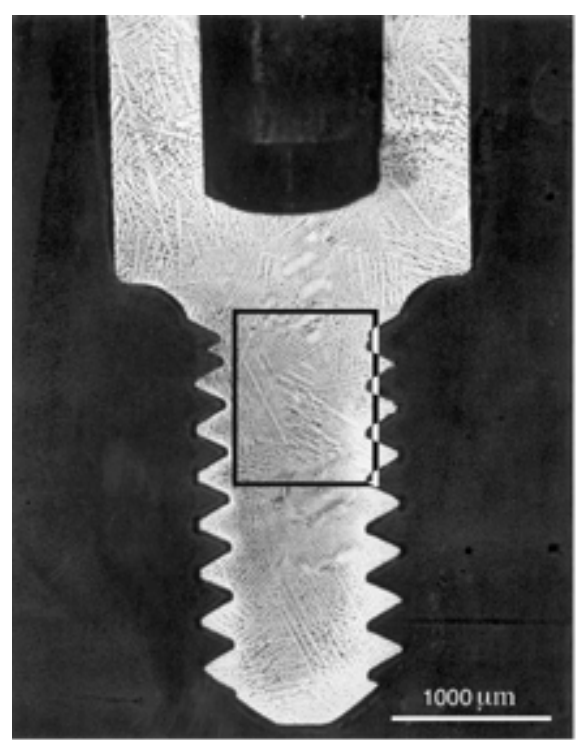

(A)

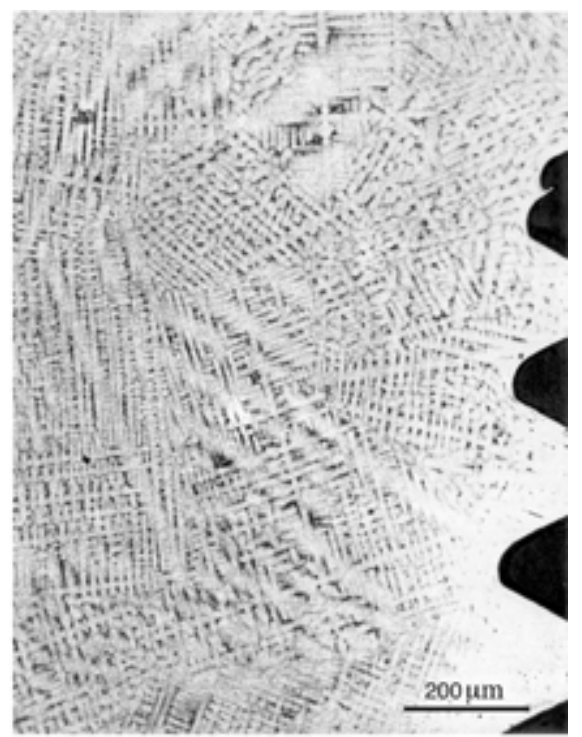

(B)

Figure 12. Light micrograph after etching of $12 \mathrm{~A}_{3}$ screw showing typical dendritic solidification microstructure: (A) at $\times 25$, (B) at $\times 100$ of outlined area in (A).

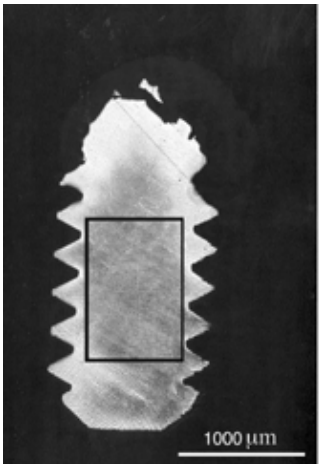

(A)

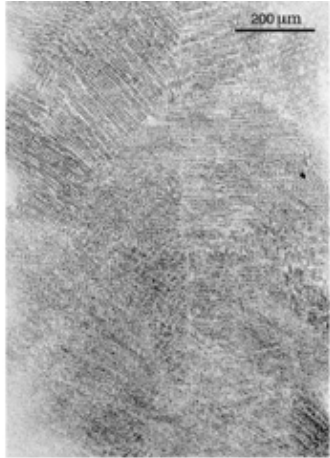

(B)

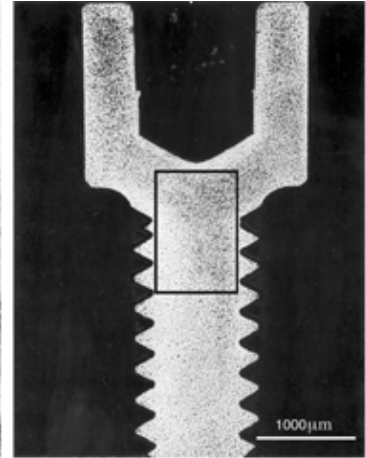

(C)

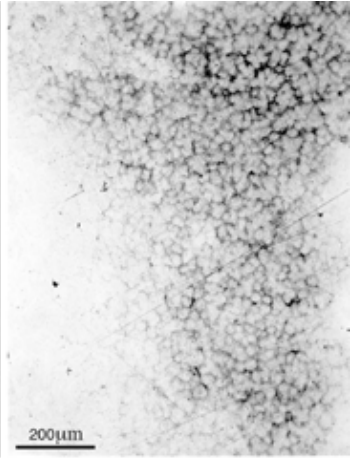

(D)

Figure 13. Shows same as in Figure 12, but with different dendritic solidification microstructures; (A) Threaded part of fractured $16 A_{3}$ screw at $\times 25$, (B) outlined area in (A) at $\times 100$; (C) $13 A_{3}$ screw at $\times 25$, and (D) outlined area in (C) at $\times 100$. 


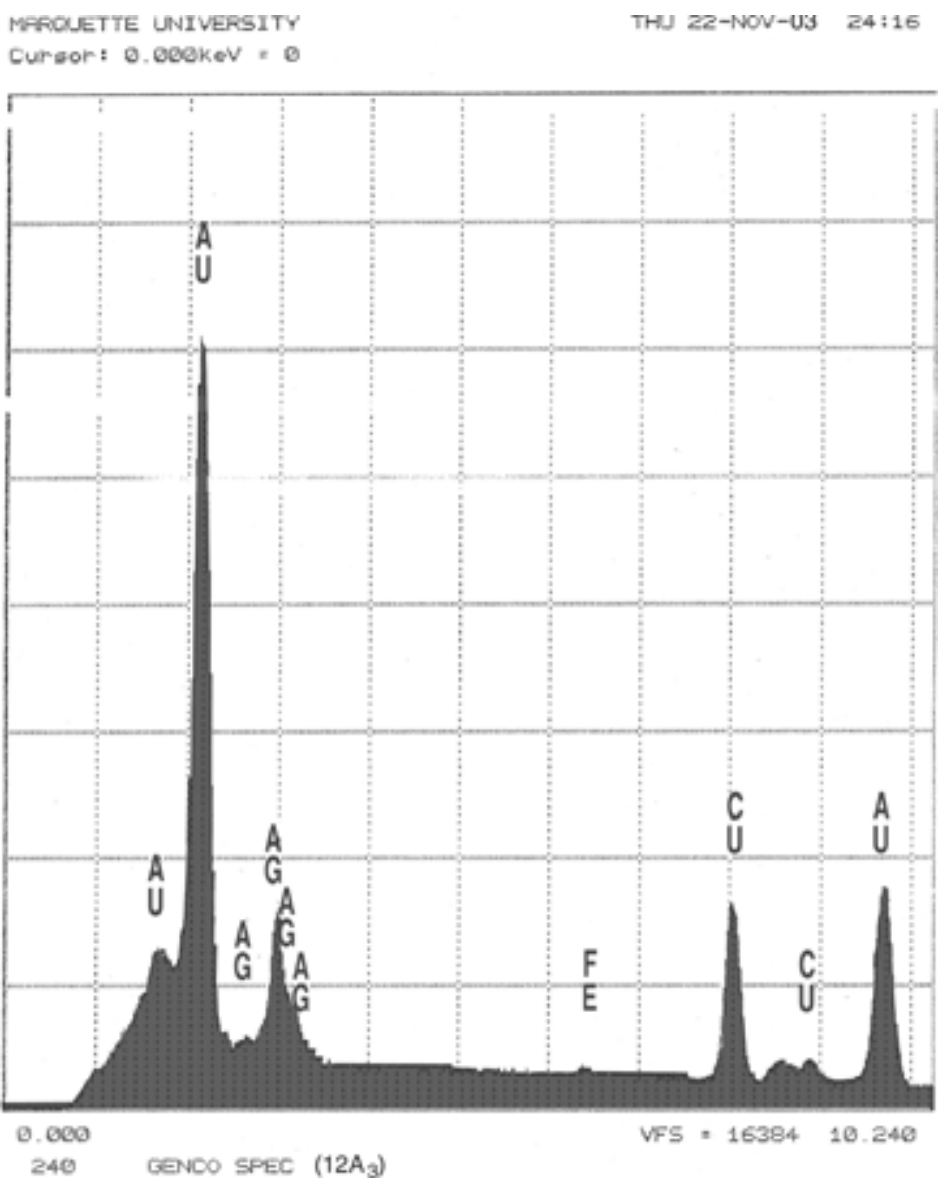

Figure 14. EDX X-ray spectrum for the overall structure of $12 A_{3}$ screw shown in Figure 12.

Figure 7 shows the microstructure screws from Groups 5 (slotted) and 8 (hexed) at low and high magnifications $(\times 25, \times 200)$. The microstructure of Groups 5 and 8 is uniform, with second phase particles at head, shank, and middle parts of threaded areas being elongated along the screw axis as a result of hot or cold working. Under higher magnification $(\times 200)$ of the thread area, wavy flow lines were observed. The flow lines were formed by fine elongated grains and follow the individual thread contour, indicating that the threads were formed by rolling (roll threading). All the etched screw surfaces for Groups 3, 6, and 10 appeared similar to what is seen in Figure 7.

Figure 8A shows the average composition of the metal alloy of Group 1 screws (control). The specimen is mainly composed of gold $(\mathrm{Au})$, platinum $(\mathrm{Pt})$, copper $(\mathrm{Cu})$, and silver $(\mathrm{Ag})$. The average composition exhibited a high weight percentage of $\mathrm{Au}(66)$ and lower weight percentages of Pt (16), $\mathrm{Cu}$ (9), and $\mathrm{Ag}$ (8). Additionally, the composition of the second phase stringer particles was determined. The SEM micrograph $(\times 3000)$ and X-ray spectra of the analyzed second phase particles are shown in Figure 8B. Compared with the average composition, the second phase particles exhibited totally different peaks with different relative intensities. The second phase particles are mainly composed of iridium (Ir) and $\mathrm{Cu}$. Au and Ag may or may not be present (these peaks are overlapped by the Ir peaks). The X-ray spectra and general composition of specimens from Groups 2, 3, 5-11, 15, and 18 were similar to those seen in Group 1. The weight percentages of the specimens from each group are shown in Table 1.

Figure 9 shows the microstructure of an etched specimen of Group 4 at low and high magnifications $(\times 25, \times 500)$. The microstructure is not homogeneous, with dark and light etching areas forming wide flow lines along the screw axis, indicating cold or hot working. The internal crack-like defect (seam) (Fig 1) is revealed more clearly by 
etching. Under higher magnification $(\times 500)$, the microstructure appeared complex and very inhomogeneous with irregular dark and light areas. Additionally, higher magnification revealed an anomalous grain structure with a distribution of large and small grain sizes and an irregular dispersion of precipitate phase around grain boundaries and selective crystallographic planes within the grains, indicating that the alloy was quenched and aged. Multiphase particles in thread areas appeared elongated along the screw axis with no deformation, indicating that the threads were formed by machining. For Group 4, the X-ray spectra from the dark and light etching areas are shown in Figure 10. The two areas exhibited very similar peaks with similar intensities. Both areas are composed mainly of palladium $(\mathrm{Pd})$, gallium $(\mathrm{Ga})$, and $\mathrm{Cu}$, with the average composition having a higher weight percentage of $\mathrm{Pd}$ and lower weight percentages of $\mathrm{Ga}, \mathrm{Cu}$, and $\mathrm{Au}$. The X-ray spectrum from the multiphase particles was very similar to the X-ray spectra for dark and light areas.

Figure 11 shows the microstructure of an etched specimen from Group 19 at low and high magnifications $(\times 25$, $\times 500)$. The microstructure at low magnification indicates cold/hot working and thread machining. High magnification $(\times 500)$ revealed homogeneous equiaxed grains with elongated multiphase regions and a regular dispersion of precipitate phase within the grains. Figure $11 \mathrm{C}$ is a high magnification SEM micrograph at $\times 2700$ showing the complex microstructure of the multiphase region consisting of what appears to be a gray matrix with precipitates, some of which exhibit a needle-like structure. The X-ray spectra from a Group 19 specimen were very similar to what was observed in Figure 10. The composition of both the matrix grains and the multiphase regions were found to be very similar to those seen in Group 4. Table 1 shows the composition and weight percentages of detected elements for Groups 4 and 19.

Figure 12 shows the microstructure of an etched specimen from Group 12. It exhibits a typical dendritic structure and associated segregation, often referred to as "coring," a very common presentation for alloy castings solidified under normal conditions. High magnification revealed a relatively consistent pattern of coring within each grain. Figure $13 \mathrm{~A}$ and $\mathrm{B}$ illustrate the threaded part of a fractured screw in Group 16 and reveal a microstructure similar to that seen in Figure 12, but with a finer dendritic structure that is probably related to variations in cooling conditions during casting. The finer dendritic arm spacing indicates a faster cooling rate and solidification time. 5 The dendritic structure of an etched specimen from Group 13 appeared globular (Fig 13C, D). The average composition of the metal alloys for Group 12 is shown in Figure 14. $\mathrm{Au}, \mathrm{Cu}$, and $\mathrm{Ag}$ were the main components of the alloy with weight percentages of 76, 14, and 9, respectively. The X-ray spectra and general composition of specimens for Groups 13, 14, 16, 17, and 20 were similar to those seen in Figure 14. Table 1shows the composition and weight percentages of the detected elements for each group.

\section{Microhardness testing}

The results of microhardness measurements of the overall average hardness of specimens from each group are presented in Table 2. Figure 15A illustrates a Vickers diamond pyramid indentation resulting from a 600-g load covering a large area and several grains of the material. As such, the hardness determined is representative of the overall hardness of the alloy. Pd alloy screws from NB (Groups 4 and 19) demonstrated no significant difference in microhardness values between multiphase regions and the surrounding matrix. Figure 15B and $\mathrm{C}$ show the small indentations that resulted from $25-\mathrm{g}$ loads falling entirely within single multiphase regions. The similarity between indentation sizes in Figure 15B and C suggests that the hardness of multiphase regions and surrounding matrix is similar.

Table 2. Overall average Vickers microhardness (VHN) measurements for each prosthetic screw group

\begin{tabular}{c|c|} 
Group number & Overall hardness \\
1 & $272 \pm 14$ \\
\hline
\end{tabular}




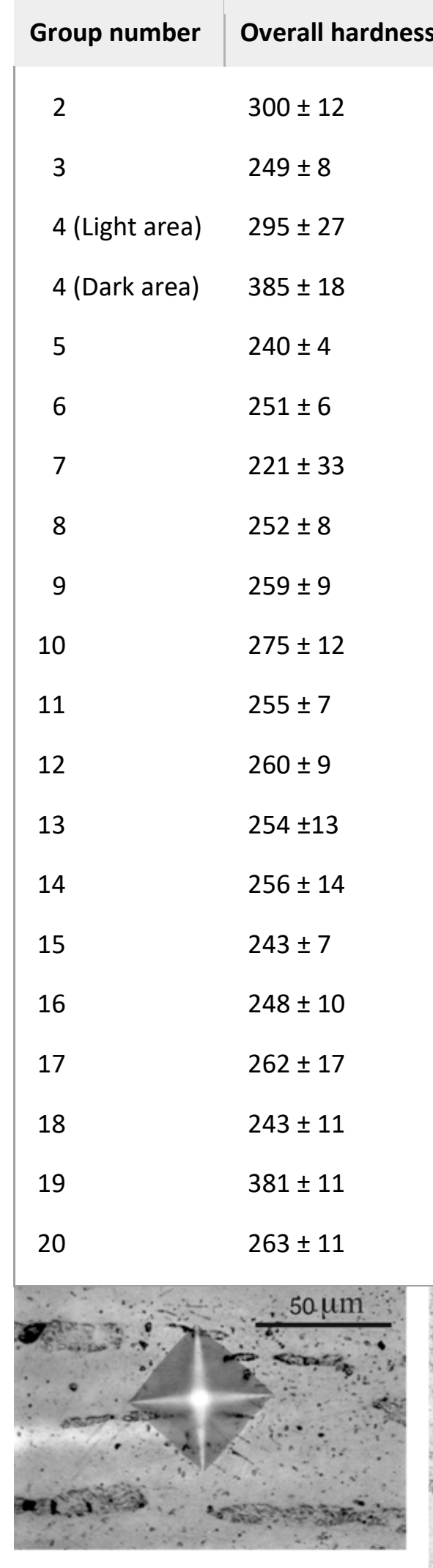

(A)

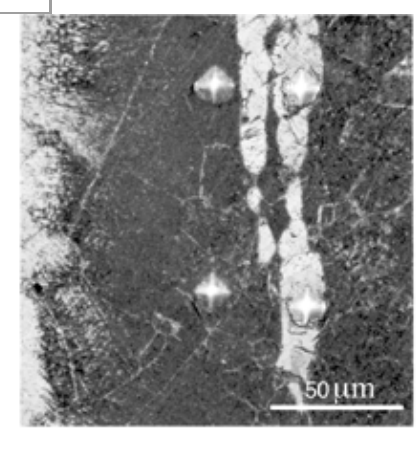

(B)

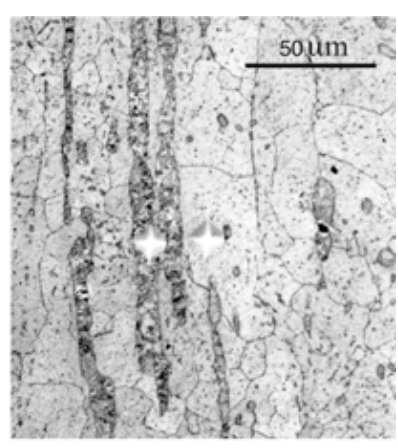

(C)

Figure 15. (A) Light micrograph (500X) of a specimen from palladium alloy screw in Group 19 tested with a Vickers diamond pyramid indenter loaded with $600 \mathrm{~g}$ to determine the overall microhardness of the alloy. (B) 
and (C) Light micrographs of specimens from a palladium alloy screws in Groups 4 (B) and 19 (C), tested with a Vickers diamond pyramid indenter loaded with $25 \mathrm{~g}$ to determine the microhardness of the multiphase region and surrounding matrix of the alloy for comparison.

\section{Discussion}

The microstructural observations, EDX analysis, and microhardness results for the various implant-retaining screws clearly show that there are significant differences in the composition, microstructure, and mechanical properties of screws from different manufacturers as well as from the same manufacturer. These differences indicate that there may be some compatibility issues regarding interchangeable use of different screws. Unlike other dental alloys used for fixed/removable partial dentures and orthodontic wires, there is no documentation regarding different alloy systems used for making implant-retaining screws. Neither names nor classifications of alloy types for implant-retaining screws are presently available, and names are primarily manufacturer-based.

Only one study has previously attempted metallurgical evaluation of retaining screws, and the microstructural and EDX X-ray spectrum observations for gold alloy retaining screws from NB in the present study are in agreement with that study. ${ }^{4}$ The EDX analysis of Au screws from NB shows that there were about 68 wt\% Au, 14 wt\% Pt, 9 wt\% Ag, and 8 wt\% Cu. The Au-Pt, $\mathrm{Au}-\mathrm{Ag}$, and Au-Cu binary phase diagrams 6 and the Au-Ag-Cu ternary phase diagram6 suggest that the alloy of the Au alloy retaining screws from NB is apparently a face-centered cubic ( $\mathrm{fcc}$ ) single phase solid solution of $\mathrm{Au}, \mathrm{Pt}, \mathrm{Cu}$, and $\mathrm{Ag}$, which may be precipitation hardened. Verification of precipitate hardening requires transmission electron microscopy (TEM), which is beyond the scope of this study. In the 1990s, Au alloys containing Pt were developed as Pd-free for dental applications primarily for full cast and ceramometal restorations.7 The phases in the second-phase stringers observed in Au alloy retaining screws from NB (Fig 6C) could not be identified, because the phase diagram data are not available for any Ir-containing binary or ternary systems, which may indicate that Ir has low solubility in Au.

The structure of the Au alloy screw from Sterngold (SG) is an fcc Au-Ag-Cu solid solution, based on the observation that the alloy has what appears to be a single phase dendritic structure (Figs 12, 13), the composition presented in Table 1 , and the Au-Ag-Cu ternary phase diagram. ${ }^{6}$

The EDX analysis of Pd screws from NB in Groups 4 and 19 (Table 1) shows that there was about 11 wt\% Cu present. It has been reported that the addition of $\mathrm{Cu}$ to the $\mathrm{Pd}-\mathrm{Ga}$ alloy increases the hardness and strength of the alloy by decreasing the solubility of $\mathrm{Ga}$ in $\mathrm{Pd}$, resulting in an increase of the eutectic constituent in $\mathrm{Pd}-\mathrm{Ga}$ alloy.8 Accordingly, the observed elongated multiphase structures in Groups 4 and 19 of this study were assumed to be eutectic material formed during original casting and retained even after heat treatment. During the wire drawing stage (cold working) of the screw manufacturing process, it is presumed that the eutectic phases elongated and became stringers. A recent study found that it is difficult to quantitatively analyze the elements in the eutectic phases using an electron microprobe because of their small size in the eutectic microstructure. ${ }^{9}$ Therefore, our finding that the X-ray spectra of multiphase regions in Groups 4 and 19 were similar to the X-ray spectra of the bulk matrix (average composition) of the Pd alloy needs to be confirmed by TEM. As mentioned previously, the use of TEM is beyond the scope of this study.

In the present study, the microstructure of Pd alloy for Group 19 (Fig 11C) exhibited a needle-like precipitate structure with a light surrounding area. This is in agreement with previous findings. ${ }^{8}$ If Ga is added to Pd-based alloy, it will form a lamellar eutectic structure that contains alternating layers of the fcc Pd solid solution and the orthorhombic $\mathrm{Pd}_{2}$ Ga-based phase. ${ }^{8,10,11}$ Therefore, considering the wrought microstructures presented in Figures 9 and 11 for the Pd alloy screws in this study, it is likely that their higher strength and hardness compared to Au-based alloy screws for NB and SG results primarily from a combination of solid solution and precipitation strengthening. 
The flow lines and microstructural patterns observed in screw threads demonstrate two common threading methods (cut and roll threading) used during screw manufacturing. Cut threading is considered one of the oldest techniques for making threads and is the least desirable method considering thread strength and quality of finish. ${ }^{12}$ On the other hand, the roll threading process allows grains to flow and follows the contour of each individual thread, which will build compressive stress into the surface of the screw threads (critical region), resulting in greater thread strength doubling the fatigue life compared to cut threading. ${ }^{12,13}$ In this study, and as demonstrated in Part 1 of this series, there was no difference in the wear pattern between cut and rolled threads. In fact, cut threads made from stronger/harder material (Pd alloy) showed less wear than rolled threads made from Au alloy. This suggests that for retaining screws, the material type is more important than the type of manufacturing process.

The occurrence of manufacturing defects in prosthetic retaining screws may affect their mechanical properties and/or fatigue life under in-service loading conditions. Crevices and grooves can act as stress raisers, which may lead to fatigue crack formation. Additionally, they alter the originally intended manufacturer design of malefemale thread engagement. No studies have reported the occurrence of defects and the effect of those defects on the in-service behavior of retaining screws. The observed external crack in Part 1 and internal crack-like defects in this study involving Pd alloy retaining screws of Group 4 were considered to be "seams," which originated as a "hot tear" during original casting solidification and became seams during wire swaging or drawing. This observation is consistent with what has been previously reported for commonly used dental palladium alloy material. ${ }^{10,14}$ In general, hot tears were created shortly after metal solidification as a result of newly formed contraction stresses making "hot tears" a source of weakness and fatigue fracture initiation in regions under static and cyclic loading. ${ }^{5,14}$ Surprisingly, the screws having seams in this study served clinically in vivo for 10 years with no fatigue crack formation and/or premature failure. This was probably because seams were located in the middle along the long axis of each screw, making the main tensile forces parallel to the crack. In large fasteners, external tears usually are not important in failure analysis, because they connect with the surface, making them easy to detect and reject by quality control and/or final users; however, in a very small fastener such as a retaining screw, the detection of external tears is extremely difficult with the unaided eye. Accordingly, manufacturers should consider using magnification procedures to detect external cracks before distributing prosthetic retaining screws to clinicians. Internal tears, on the other hand, are extremely important in failure analysis, because they may go undetected unless some sort of nondestructive inspection like $\mathrm{X}$-ray radiography is applied; however, because prosthetic retaining screws are very small, the detection of such a defect using radiography or other technologies may not be possible.

\section{Clinical significance}

Significant differences were found for microstructure and major alloy constituents between NB and SG screws and within NB screws. Some screws were made from Au-based alloys and others from Pd-based alloys. With regard to terminology, "gold screw" is sometimes used to refer to the prosthetic retaining screw. Based on this study and previous findings of other studies, retaining screws are not always made from Au and, therefore, the clinician should be very careful and specific when using the term "gold screw" to avoid confusion. This is important because different alloys have different mechanical properties.

With the exception of dental implants, dental materials in other fields of dentistry have well known and written specifications regarding their composition and mechanical properties. This allows clinicians to evaluate and choose the appropriate materials for specific applications. It is not clear why there is still a lack of standard specifications for implant materials. Implant dentistry is not a new field, as implants have been in clinical use for about 40 years with a success rate approaching $99 \%$. The great variability of geometrical designs, alloy constituents, microstructure, and mechanical properties requires that the American Dental Association (ADA) and/or clinicians demand standard specifications for prosthetic implant components provided by each implant 
system manufacturer. Only after using this background data and information can interchanging component hardware between implant systems be considered acceptable. Without standard specifications, clinicians cannot track/record the alloy and its complete composition. Accordingly, clinicians cannot determine and/or avoid elements to which their patients are allergic. The notion of allergic reactions should be enough to require full description of alloy composition from implant manufacturers. In this study, trace elements in the alloy of prosthetic retaining screws varied considerably within the NB screws and between screws from NB and SG.

In this study, Pd alloy retaining screw samples from NB had the longest clinical in-service time (10 years), whereas the gold alloy retaining screws from NB had only up to 5 years in-service time. This suggests that $\mathrm{Pd}$ alloy retaining screws were one of the earliest generations introduced to the market by NB (Branemark at that time) before the introduction of Au alloy screws. Most likely, NB made the transition from Pd to Au alloy screws to avoid the high coefficient of friction between the Pd material of the retaining screw and the abutment screw, limiting and reducing the final preload value of the retaining screw as observed in Part 3 of this series. In 2003, in an effort to further reduce frictional resistance, NB introduced a new coated retaining screw (Torque Tite ${ }^{\circledR}$ ) that increases the final preload value. In the fastener industry, coating technology covers the entire standard screw with up to $0.76 \mu \mathrm{m}$ of coating material. Part 1 of this series suggests that galling is an unavoidable fact, which may lead to the wear of the coating material, and therefore the effectiveness of this coating on the stability of the clamped joint should be the focus of future studies and clinical trials, reinforcing a similar previous suggestion regarding the effectiveness of coating technology. ${ }^{2}$ Similarly, if the suggested maintenance protocol of Part 1 of this series is followed directing repeated annual torquing/untorquing of the retaining screws, the effectiveness of this coating should be the focus of future studies.

\section{Conclusions}

It can be concluded from this study that:

1 Significant differences within NB retaining screws and between NB and SG screws were found for manufacturing process, microstructure, major alloy constituents, and microhardness.

2 The occurrence of severe plastic deformation of retaining screws will lead to the formation of unwanted crevices and grooves, which may act as stress raisers.

3 The occurrence of significant manufacturing defects on prosthetic retaining screws, which might adversely affect their mechanical properties and behavior, should be considered uncommon.

\section{Acknowledgments}

The authors thank Dr. Charles Goodacre for his valuable input during the writing of this manuscript. The authors also thank Jim Brozek for his assistance in formatting the photographs and illustrations.

\section{References}

1 Martin WC, Woody RD, Miller BH, et al: Implant abutment screw rotations and preloads for four different screw materials and surfaces. J Prosthet Dent2001;86:24-32

2 Binon PP: Implants and components: entering the new millennium. Int J Oral Maxillofac Implants 2000;15:7694

3 Porter S, Robb T: Increasing implant-abutment preload by thin gold coating abutment screws [abstract]. J Dent Res 1998;77:837

4 Rambhia KS, Nagy WW, Fournelle RA, et al: Defects in hexed gold prosthetic screws: a metallographic and tensile analysis. J Prosthet Dent 2002;87:30-39

5 Colangelo VJ, Heiser FA: Analysis of Metallurgical Failures (ed 2). New York, NY , Wiley, 1987 
6 Phase diagrams. ASM Handbook, vol 3, (ed 4). Materials Park, OH, ASM International, 1992

7 Wataha J: Alloys for prosthodontic restorations. J Prosthet Dent 2002;87:351-363

8 Brantly WA, Cai Z, Carr AB, et al: Metallurgical structures of as cast and heat-treated high-palladium dental alloys. Cells Mater 1993;3:103-114

9 Mezger P, Stols A, Vrijhoef M, et al: Metallurgical aspects of high-palladium alloys. J Dent Res 1988;67:13071311

10 Carr AB, Brantly W: New high-palladium casting alloys: part 1. Overview and initial studies. Int J Prosthet 1991;4:265-275

11 Papazolgou E, Wu Q, Brantly W, et al: Mechanical properties of dendritic Pd-Cu-Ga dental alloys. Cell Mater 1999;9:43-45

12 Bickford J, Nassar S: Handbook of Bolts and Bolted Joints. New York, NY , Marcel Dekker, 1998

13 Bickford JH: An Introduction to the Design and Behavior of Bolted Joints (ed 3). New York, NY, Marcel Dekker, 1995

14 Carr A, Brantly W, Mitchell J: New higher-palladium casting alloys: part 2. Effects of heat treatment and burnout temperature. Int J Prosthodont1993;6:233-241 